Article

\title{
Economic Feasibility of Underground Pumped Storage Hydropower Plants Providing Ancillary Services
}

\author{
Javier Menéndez ${ }^{1, *(0)}$, Jesús Manuel Fernández-Oro ${ }^{2} \mathbb{D}$ and Jorge Loredo ${ }^{3}$ \\ 1 Hunaser Energy, Avda. Galicia 44, 33005 Oviedo, Spain \\ 2 Energy Department, University of Oviedo, 33271 Gijón, Spain; jesusfo@uniovi.es \\ 3 Mining Exploitation Department, University of Oviedo, 33004 Oviedo, Spain; jloredo@uniovi.es \\ * Correspondence: jmenendezr@hunaser-energia.es; Tel.: +34-98-510-7300
}

Received: 14 May 2020; Accepted: 5 June 2020; Published: 6 June 2020

check for updates

\begin{abstract}
The electricity generated by some renewable energy sources (RESs) is difficult to forecast; therefore, large-scale energy storage systems (ESSs) are required for balancing supply and demand. Unlike conventional pumped storage hydropower (PSH) systems, underground pumped storage hydropower (UPSH) plants are not limited by topography and produce low environmental impacts. In this paper, a deterministic model has been conducted for three UPSH plants in order to evaluate the economic feasibility when considering daily turbine cycle times at full load (DTCs) between 4 and $10 \mathrm{~h}$. In the model, the day-ahead and the ancillary services markets have been compared to maximize the price spread between the electricity generated and consumed. Secondary regulation, deviation management and tertiary regulation services have been analyzed to maximize the income and minimize the cost for purchasing energy. The capital costs of an open-loop UPSH plant have been estimated for the case of using the existing infrastructure and for the case of excavating new tunnels as lower reservoirs. The net present value (NPV), internal rate of return (IRR) and payback period $(\mathrm{PB})$ have been obtained in all scenarios. The results obtained show that the energy generation and the annual generation cycles decrease when the DTC increases from 4 to $10 \mathrm{~h}$, while the NPV and the IRR increase due to investment costs. The investment cost of a 219 MW UPSH plant using the existing infrastructure reaches $366.96 \mathrm{M} €$, while the NPV, IRR and PB reached $185 \mathrm{M€}, 7.10 \%$ and 15 years, respectively, participating in the ancillary services markets and considering a DTC of $8 \mathrm{~h}$.
\end{abstract}

Keywords: energy storage; underground pumped storage; economic feasibility; ancillary services; day-ahead market; underground space

\section{Introduction}

The rapid growth of intermittent renewable energy sources (RESs) for electricity generation requires flexible large-scale energy storage systems (ESSs). Electricity generated by some forms of RESs, such as wind or solar photovoltaic (PV), is difficult to forecast; therefore, ESSs are required for balancing electricity supply and demand [1]. Pumped storage hydroelectricity (PSH) is the most mature and efficient storage technology and accounts for $98 \%$ of storage capacity worldwide [2]. However, the development of new PSH projects is limited by topographic and environmental restrictions. Thus, disused underground space may be used as reservoir for large-scale storage systems such as underground pumped storage hydropower (UPSH) or adiabatic compressed air energy storage (A-CAES) $[3,4]$ where the typical round trip energy efficiencies exceed $0.7-0.8[5,6]$. Unlike conventional PSH plants, which consist of two water reservoirs located at the surface, both upper and lower reservoirs may be underground in the case of UPSH plants. For that purpose, two different options may be 
considered: (1) to make use of existing infrastructure; or (2) to dig new tunnels. Winde et al. $[7,8]$ explored the use of deep-level gold mines in South Africa for UPSH schemes. Pujades et al. $[9,10]$ carried out a study considering the use of a closed slate mine located at Belgium with a capacity of $550,000 \mathrm{~m}^{3}$ as a lower reservoir for UPSH. Bodeux et al. [11] analyzed the interactions between groundwater and the slate chambers used as a subsurface water reservoir. Closed coal mines in Spain and Germany have also been proposed as underground reservoirs for UPSH [12-15]. Wong [16] proposed digging new tunnels or shafts as a lower reservoir for UPSH in the Bukit Timah granite of Singapore. The economic feasibility of UPSH plants depends on the capital costs and the price spread between the electricity generated and consumed in turbine and pumping modes, respectively. In the Iberian electricity system, RES generation is granted priority during the dispatch and receives a fixed feed-in tariff. The day-ahead prices (spot prices), are set around noon on the day preceding the delivery. The day-ahead markets are complemented by intraday markets and ancillary services in the case of unforeseen events and changing weather conditions, which mainly could affect wind and solar PV generation. Finally, the balance of the electricity demand and supply is achieved through the ancillary services, which are managed by the system operator, taking the form of auctions in the Iberian electricity system.

Traditionally, a PSH plant has been operated by the price-arbitrage strategy. PSH plants have participated in the day-ahead market, selling the electricity generated at peak periods (peak price hours) and purchasing the electricity at off-peak periods [17,18]. However, the electricity price spread between the on-peak periods and off-peak periods has been reduced significantly, and the economic feasibility of a PSH might not be guaranteed participating just in the day-ahead electricity market. Lobato et al. [19] carried out an overview of ancillary services in Spain, including a technical description and the management of the ancillary services markets. The study highlights the paramount importance of the ancillary services in a power system. Pérez-Díaz et al. [20] reviewed the trends and challenges of PSH plants with the aim of optimizing their operation in the balancing markets. The study showed that ancillary services markets, particularly those related to balancing supply and demand, emerge as a valuable source of income for PSH plants.

Krishnan and Das [21] studied the feasibility of CAES plants participating in the day-ahead and balancing markets of PJM and Midcontinent Independent System Operator (MISO), concluding that the profit may be increased 10-fold by providing ancillary services. Berrada et al. [22] estimated the income of different ESSs (PSH, CAES and gravity energy storage) that participate in the day-ahead market, the real-time energy market and the regulation market of the New York Independent System Operator (NYISO). The results obtained showed that PSH and CAES may be economically feasible when operating in the regulation market. Chazarra et al. [23] studied the economic viability of twelve PSH plants participating in the secondary regulation of the Iberian electricity system. The PSH plants were equipped with different fixed-speed and variable-speed units and with and without considering hydraulic short-circuit operation. They concluded that PSH plants equipped with variable speed technology, along with full converters with and without the possibility to operate in hydraulic short-circuit mode, and the PSH plants with ternary units obtain the lowest payback periods.

Recently, Maciejowska et al. [24] developed a model that is able to predict the price spread between the day-ahead prices and the corresponding volume-weighted average intraday markets in the German electricity system. The research concluded that the sign of the price spread can be successfully predicted with econometric models, such as ARX and probit. Ekman and Jensen [25] conducted a study of a generic ESS with a global energy efficiency of 0.7 participating in the day-ahead market and some balancing markets in Denmark. They concluded that only UPSH might be profitable as long as it participates both in the day-ahead and ancillary services markets. The contribution of a variable speed PSH to increasing the revenue has been assessed for participation in the day-ahead and secondary regulation reserve markets in the Iberian electricity system [26]. Chazarra et al. [27] developed a stochastic model for the weekly scheduling of a hydropower system to optimize the revenue in the Spanish electricity system. The obtained solution protects a multireservoir system against risk of water 
and storage unavailability. The effect of the complementarity between the variable renewable energy sources and the load on the flexibility of the power system was examined in the Korean electricity system [28]. They examined an optimal mix ratio between the wind and solar PV and concluded that the ratios of the wind and solar PV to the total variable generation resource were $1.3 \%$ and $93.4 \%$, respectively. Lago et al. [29] proposed a deep neural network by using Bayesian optimization and functional analysis of variance to improve the predictive accuracy in a day-ahead energy market. Chazarra et al. [30] estimated the maximum theoretical income of a PSH plant participating as a price-taker in the day-ahead and the secondary regulation reserve markets while considering different configurations of power plants in the Iberian electricity system. The results obtained demonstrate that the operation with the variable speed technology could be of considerable help in enlarging the income of the hydropower plant.

In this work, the economic feasibility of three UPSH plants is analyzed considering DTCs between 4 and $10 \mathrm{~h}$. The generation and consumption of electricity and the number of annual generation cycles have been estimated assuming a round trip energy efficiency of 0.77 . The day-ahead and ancillary services markets in the Iberian electricity system are analyzed for optimizing the profitability of investment. Secondary regulation, deviation management and tertiary regulation services have been considered to maximize the income from selling energy and minimize the cost for purchasing energy. The capital costs of UPSH plants have also been calculated for the first time, considering the case of using the existing infrastructure and the case of excavating new tunnels or caverns as a lower water reservoir. Finally, a profitability analysis has been carried out using the net present value (NPV), internal rate of return (IRR) and payback period (PB).

\section{Methodology}

A three-step scheme of the methodology proposed to study the economic feasibility and profitability of UPSH plants is shown in Figure 1.

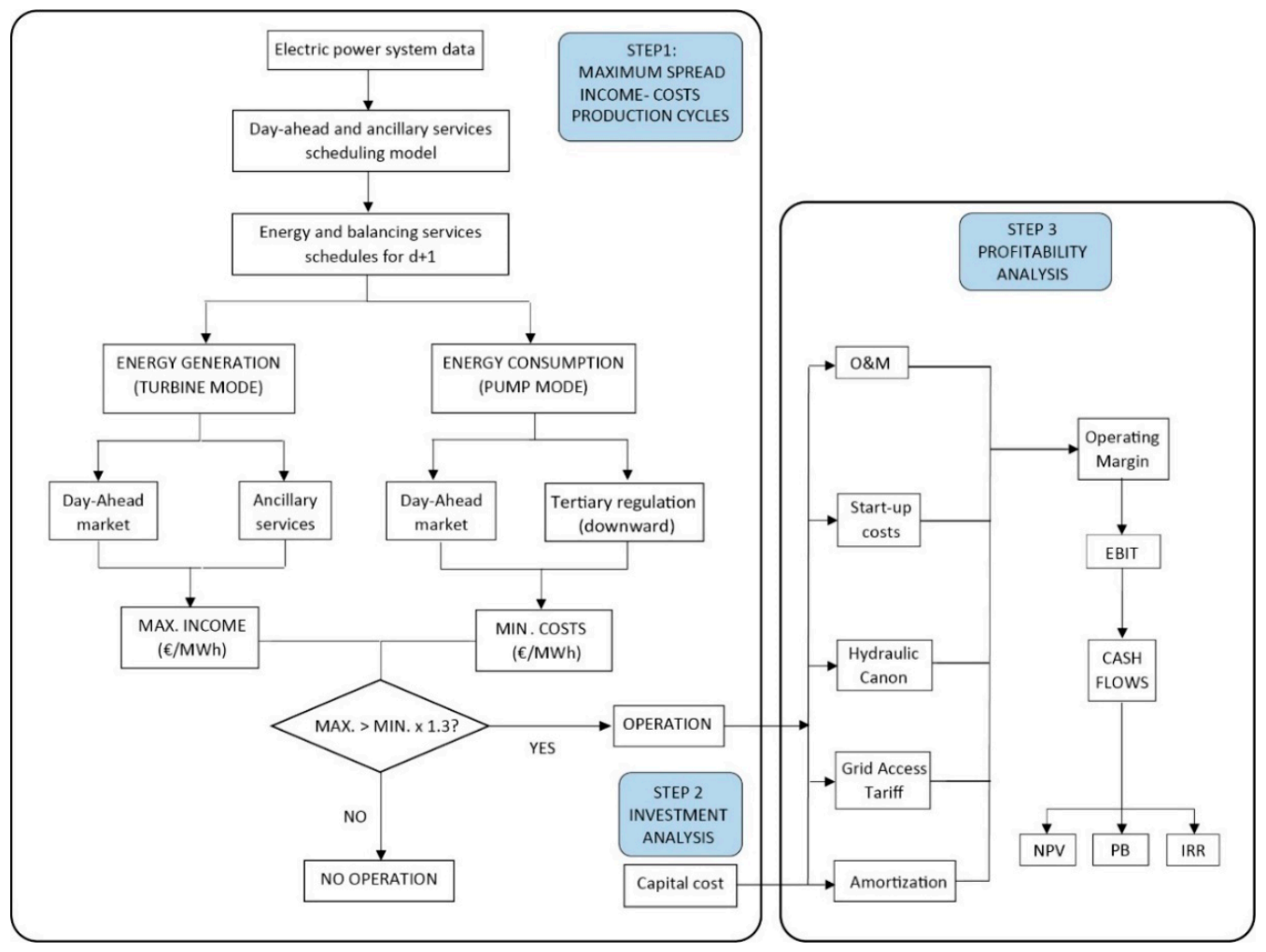

Figure 1. Methodology scheme to analyze the economic feasibility of underground pumped storage hydropower (UPSH) plants. 
The model considers the electricity prices in the day-ahead and ancillary services markets hour by hour for a time period of three years (2016-2018). In step 1, the maximum and minimum prices are analyzed for the energy generated and consumed in the Iberian electricity system, considering DTCs between 4 and $10 \mathrm{~h}$. The number of annual generation cycles and the amount of energy generated are obtained for all scenarios. In step 2, the investment costs of a UPSH plant are estimated for the case of using the existing infrastructure and the case of excavating new tunnels or caverns as a lower reservoir. Amortization costs are calculated considering a typical operation period of 35 years. Finally, in step 3, the operating margin, which is defined as the income from selling energy minus the costs for purchasing energy and the operation costs (O\&M, start-up costs, hydraulic cannon and grid access tariffs), is estimated for the three hydropower stations (HPSs) considered in this study.

The earnings before interest and taxes (EBIT) and the cash flows have been calculated to analyze the economic feasibility and the profitability. The NPV, i.e., the difference between the present value of cash inflows and the present value of cash outflows over a period of time; IRR, i.e., a discount rate that makes the NPV of all cash flows from a project equal to zero; and PB, i.e., the time in which the initial outlay of an investment is expected to be recovered, have been calculated in all scenarios.

\subsection{Technical Data of UPSH Plants}

Figure 2 shows two different schemes of UPSH plants in a closed mine. Figure 2a shows a UPSH scheme with an upper surface reservoir and an underground lower reservoir. Conversely, Figure $2 b$ depicts a shallow upper reservoir and an underground lower reservoir. Note that the gross head is reduced when a shallow upper reservoir is considered. This reduction in gross head implies a decrease in storable amount of energy.

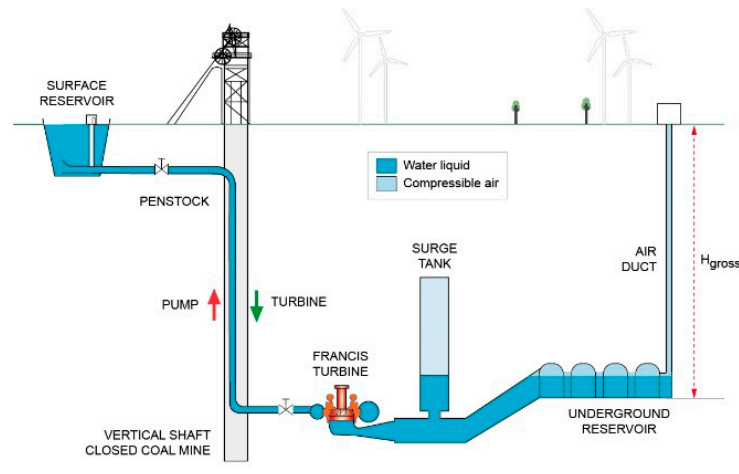

(a)

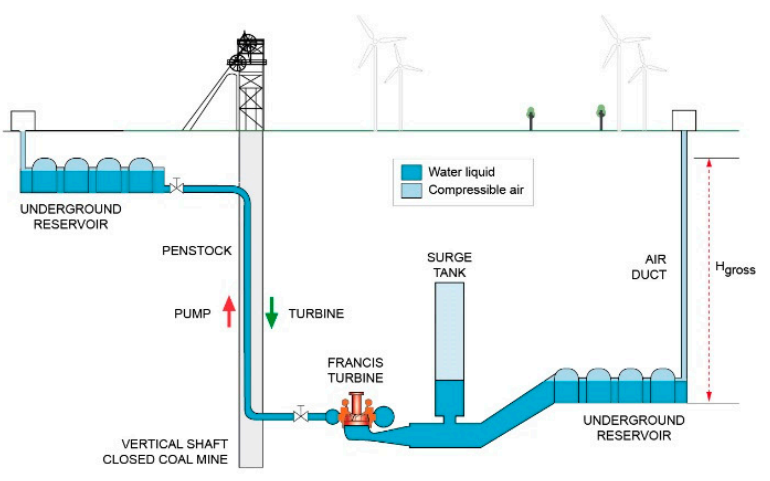

(b)

Figure 2. UPSH scheme in a closed mine. (a) Surface upper reservoir and underground lower reservoir; (b) Shallow upper reservoir and underground lower reservoir.

The technical data of the three hydropower stations (HPSs) are shown in Figure 3, considering DTCs between $4-10 \mathrm{~h} \mathrm{day}^{-1}$. The water flow rate is lower in pumping mode and therefore the pumping cycle time at full load increases to 5.40 and $13.30 \mathrm{~h} \mathrm{day}^{-1}$. The storage capacities are $0.46,0.8$ and $1.6 \mathrm{Mm}^{3}$ for HPS 1, HPS 2 and HPS 3, respectively, and remain constant in each DTC (4-10 h). Although the amount of storable energy does not vary, the output powers decrease from 125, 219 and $440 \mathrm{MW}$ to 50, 87 and $176 \mathrm{MW}$ for HPS 1, HPS 2 and HPS 3, respectively, when the turbine cycle time increases from 4 to $10 \mathrm{~h} \mathrm{day}^{-1}$. A maximum gross pressure of $4.41 \mathrm{MPa}$ has been considered. The water flow rates in turbine mode are 12.78, 22.23 and $44.45 \mathrm{~m}^{3} \mathrm{~s}^{-1}$ for HPS 1, HPS 2 and HPS 3, respectively, considering a DTC of $10 \mathrm{~h}$, while the efficiency values are 0.91 and 0.90 in turbine and pump mode, respectively. The water flow rates in pumping mode are 9.61, 16.71 and $33.42 \mathrm{~m}^{3} \mathrm{~s}^{-1}$ for HPS 1 , HPS 2 and HPS 3 , respectively, when the pumping cycle time at full load is $13.30 \mathrm{~h} \mathrm{day}^{-1}$. In addition, the round trip energy efficiency is assumed to be 0.77 [6]. 


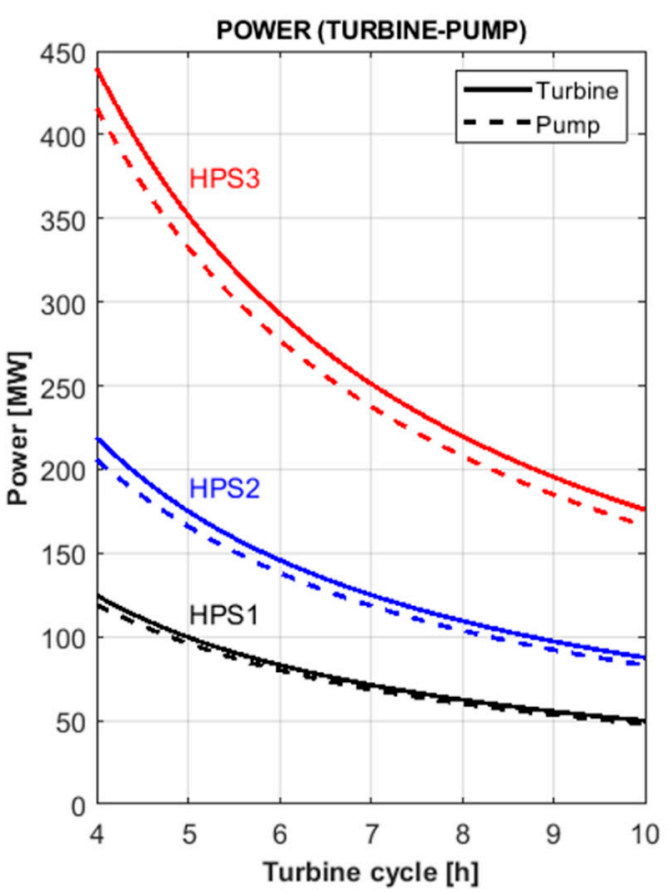

(a)

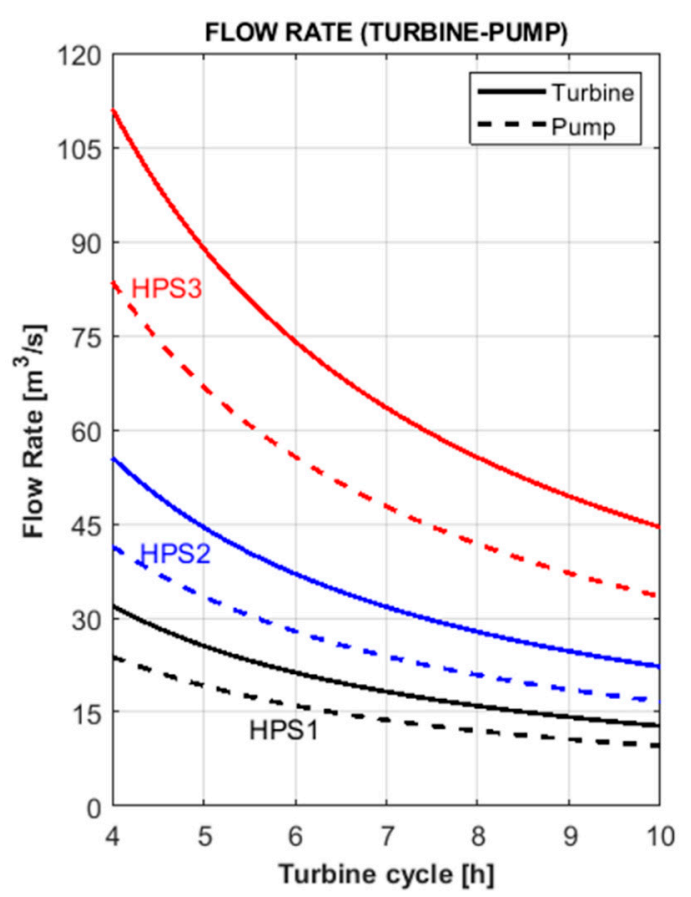

(b)

Figure 3. Technical data of HPS 1, HPS 2 and HPS 3, considering daily turbine cycle times at full load (DTCs) between 4-10 $\mathrm{h} \mathrm{day}^{-1}$. (a) Power in turbine and pump modes; (b) water flow rate in turbine and pump modes.

\subsection{Electric Power System Data}

The economic feasibility of UPSH plants is obtained considering the historical hourly values of the prices in the day-ahead and ancillary services markets in the Iberian electricity system during a period of three years (2016-2018). The main objective of this work is to estimate the maximum income from selling energy (turbine mode) and the minimum cost for purchasing energy (pumping mode) while participating in the day-ahead and balancing markets. The following markets and services for the mentioned years have been studied: (i) the day-ahead market; (ii) the upward secondary regulation; (iii) the upward deviation management; and (iv) the tertiary regulation (upward and downward).

The overall amounts of energy managed in secondary regulation, deviation management and tertiary regulation in 2018 were 2592, 2358 and $3301 \mathrm{GWh}$, respectively. The purpose of the secondary regulation service is to maintain the generation-demand balance, automatically correcting deviations with respect to the anticipated power exchange schedule and the system frequency deviations. The objective of the deviation management service is to resolve the deviations between generation and demand which could appear in the period between the end of one intraday market and the beginning of the next intraday market horizon. Finally, the purpose of the tertiary regulation service is to resolve the deviations between generation and consumption and the restoration of the secondary control band reserve used. These ancillary services are managed and remunerated by market mechanisms in the Iberian electricity system.

\section{Results and Discussion}

\subsection{Investment Cost of UPSH Plants}

In this section, the investment costs of UPSH plants are estimated for the case of using existing underground infrastructure and the case of digging new tunnels or caverns as a lower reservoir. Currently, there are no research works where the investment costs of UPSH plants are analyzed. However, several authors have studied the investment cost of conventional PSH plants. Connolly 
et al. [18] proposed a range between 0.47 and 2.17 $\mathrm{M} \mathrm{MW}^{-1}$ from projects in some countries in the European Union. Steffen [31] proposes a range between 0.77 and $1.28 \mathrm{M}^{\mathrm{M}} \mathrm{MW}^{-1}$ from projects of PSH in Germany and Luxembourg. An increase between 7 and 15\% is produced when the PSH plant is equipped with variable speed units. The investment cost of a UPSH plant depends strongly on the facility's location and type of underground infrastructure.

The investment costs of a UPSH plant in a closed mine considering the case of excavation of new tunnels and the case of using existing infrastructure are shown in Table 1. A Francis pump-turbine (FT) with a maximum output power of $219 \mathrm{MW}$ and a maximum input power of $208 \mathrm{MW}$, a water flow rate in turbine mode of $55.56 \mathrm{~m}^{3} \mathrm{~s}^{-1}$ (turbine cycle of $8 \mathrm{~h}$ at full load) and a water reservoir capacity of $1.6 \mathrm{Mm}^{3}$ have been considered. In addition, in both scenarios, due to the dimensions and weight of the hydropower equipment (FT and motor-alternator), the excavation of a new access tunnel from the surface to the powerhouse is required. This tunnel would be used during the construction and operation phases. The investment cost reaches $687.34 \mathrm{M} €$, which represents a unit cost per MW of installed power of $3138 € \mathrm{~kW}^{-1}$. The main cost corresponds to civil works, reaching 525.69 M€ and representing $76.48 \%$ of the total investment cost. The cost of excavating the new tunnels as a lower reservoir reaches $453.33 \mathrm{M} €$, which is $86.23 \%$ of the total civil works cost. Conversely, the construction and waterproofing of the upper reservoir reach $30.73 \mathrm{M} €$. More details can be found in Appendix A, where the capital cost of a UPSH plant are detailed.

When the existing infrastructure is used as a lower reservoir, the investment costs are reduced to $366.96 \mathrm{M} €$, representing $46.66 \%$ less than the previous investment cost. The existing underground infrastructure would be secured with a reinforced shotcrete layer and waterproofed. Consequently, the unit cost per MW of installed capacity is also reduced to $1675 € \mathrm{~kW}^{-1}$. The cost of civil works decreases down to $218.08 \mathrm{M} €$, which is $59.40 \%$ of the total cost. The cost of conditioning the lower reservoir reaches $145.73 \mathrm{M€}$, representing $66.82 \%$ of the total civil works cost. Electrical grid connection cost includes the electric substation located in the UPSH plant and the electric power line. The excavation materials of the upper and lower reservoirs could be used for restoring the open pit mines existing in the study area. As indicated in Figure $2 b$, both upper and lower reservoirs could be underground. In this scenario, where the environmental impact is reduced, the investment cost reaches $1076 \mathrm{M€}$.

Table 1. UPSH investment costs analysis for construction of new tunnels or caverns and for making use of existing infrastructure.

\begin{tabular}{ccc}
\hline UPSH Investment Costs $(\mathbf{k})$ & New Tunnels & Existing Infrastructure \\
\hline Civil works & $525,692.80$ & $218,083.58$ \\
Hydromechanical equipment and penstock & $16,986.52$ & $16,986.52$ \\
Hydropower equipment & $99,709.12$ & $99,709.12$ \\
Electrical grid connection & 4510.50 & 4510.50 \\
Commissioning & 4140.85 & 3767.38 \\
Project management & $36,301.30$ & $23,907.56$ \\
\hline Total (k€) & $\mathbf{6 8 7 , 3 4 1 . 1 0}$ & $\mathbf{3 6 6 , 9 6 4 . 6 7}$ \\
\hline
\end{tabular}

\subsection{Estimation of Income and Expenses}

The storable amount of energy in UPSH plants depends on the net head and the water mass moved. The maximum income from selling energy has been studied considering the amount of electricity generated in turbine mode considering the maximum prices in the day-ahead and ancillary services markets. Likewise, the downward tertiary regulation service and the day-ahead market have been analyzed to obtain the minimum price for purchasing energy. Figure 4a shows the maximum prices in the day-ahead and ancillary services and the minimum prices in the downward tertiary regulation service, considering DTCs between 4 and $10 \mathrm{~h}$. The price spread between the day-ahead and the ancillary services markets for generation and consumption modes is shown in Figure 4b. 


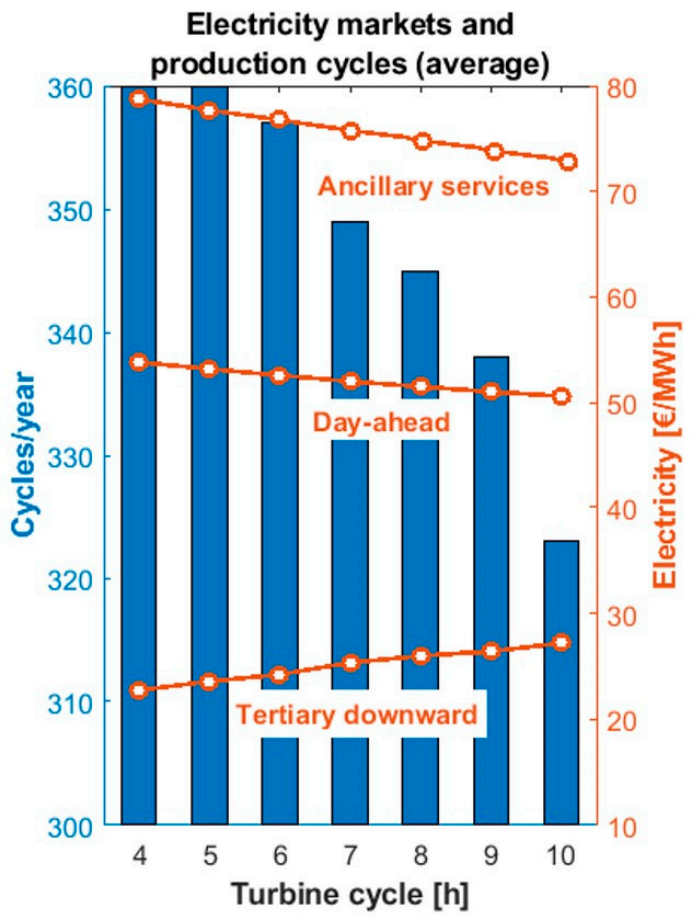

(a)

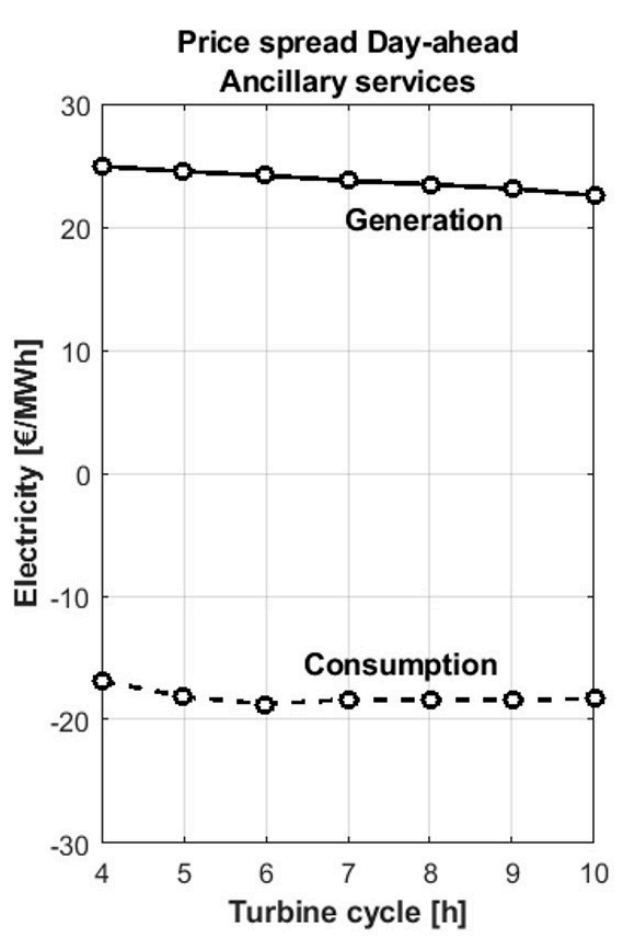

(b)

Figure 4. Analysis of electricity markets. (a) Maximum electricity prices in the day-ahead and ancillary services markets; minimum costs in the downward tertiary regulation service and annual generation cycles. (b) Price spread between the day-ahead and the ancillary services markets.

Concerning Figure 4a, the number of annual generation cycles is calculated to obtain the amount of electricity generated in turbine mode. The electricity consumed in pumping mode is estimated assuming a round trip energy efficiency of about 0.77 . The annual generation cycles decrease from 360 to 323 when the DTC increases from 4 to $10 \mathrm{~h}$. The maximum price of electricity is $78.74 € \mathrm{MWh}^{-1}$ and is reached when participating in the ancillary services markets. That value, which corresponds to a DTC of $4 \mathrm{~h}$, is progressively reduced by $7 \%$ when the DTC increases to $10 \mathrm{~h}$. The minimum price in consumption mode is $22.13 € \mathrm{MWh}^{-1}$. This cost for purchasing energy is increased by $22.81 \%$, reaching $27.18 € \mathrm{MWh}^{-1}$ when the DTC increases to $10 \mathrm{~h}$. In Figure $4 \mathrm{~b}$, it is shown that the maximum price spread between the day-ahead and the ancillary service markets in generation mode is $24.92 € \mathrm{MWh}^{-1}$. In consumption mode, the maximum price spread reaches $-16.88 € \mathrm{MWh}^{-1}$. The price spread decreases by $2.36 € \mathrm{MWh}^{-1}$ in generation mode and $1.42 € \mathrm{MWh}^{-1}$ in consumption mode when the DCT increases to $10 \mathrm{~h}$.

For the purpose of analyzing the economic feasibility of the three HPSs considered in this study, the amount of energy generated and consumed and the maximum income from selling energy in generation mode (turbine) and minimum costs for purchasing energy in consumption mode (pumping) are shown in Figure 5 for the three HPSs. The maximum income decreases while the minimum expenses increase as the DTC increases from 4 to $10 \mathrm{~h}$ (see Figure 5d). 


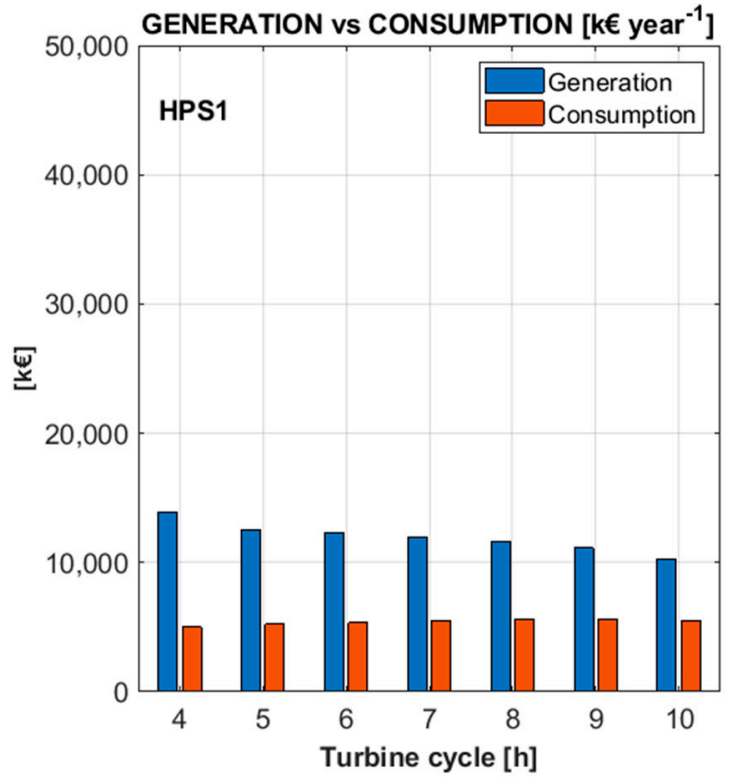

(a)

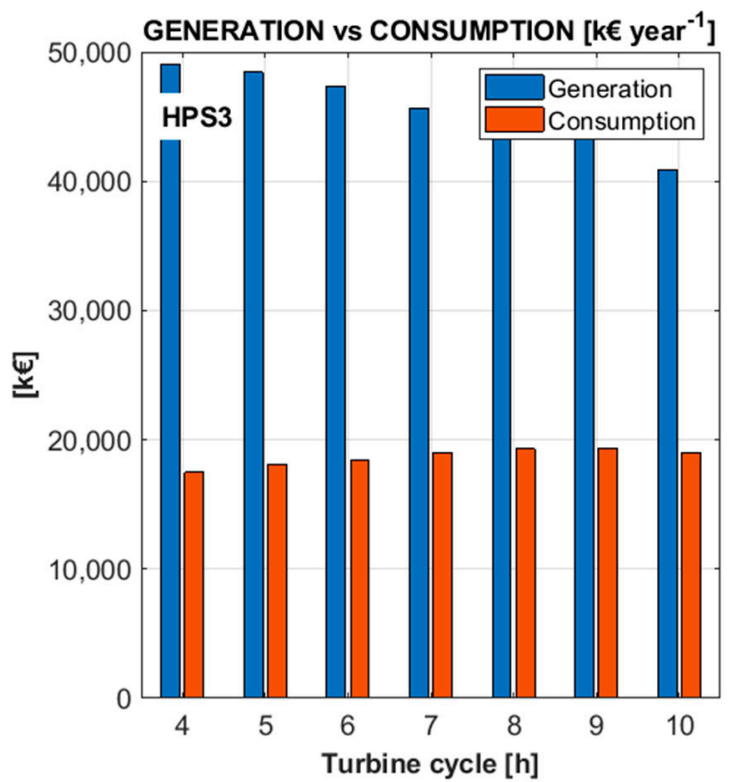

(c)

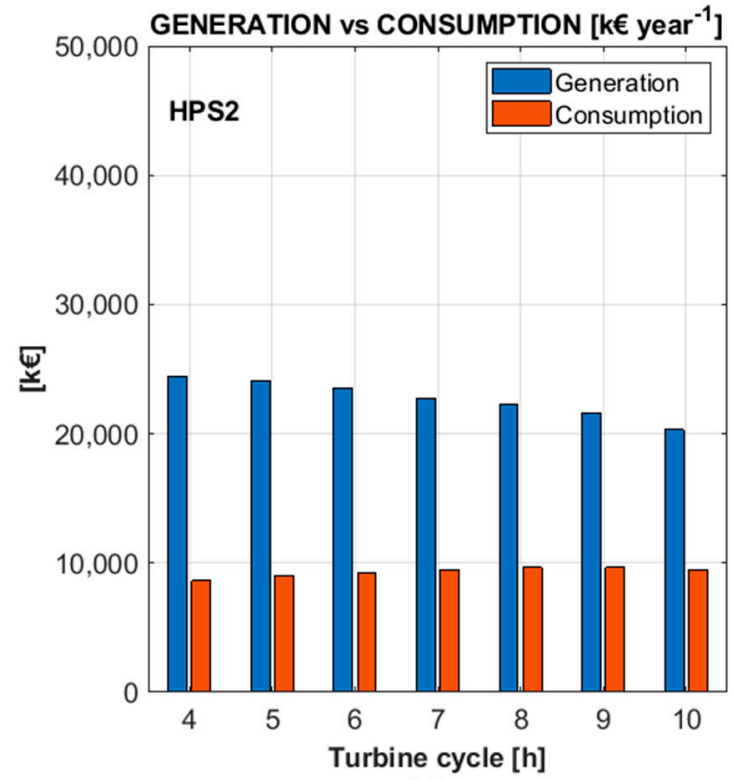

(b)

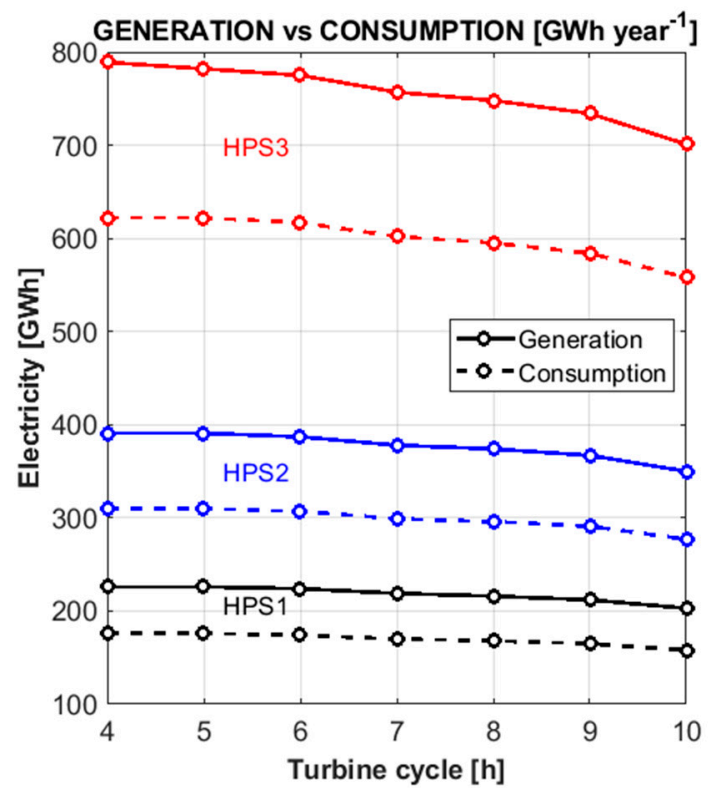

(d)

Figure 5. Maximum income from selling energy and minimum cost for purchasing energy, considering DTCs between 4 and 10 h: (a) HPS 1; (b) HPS 2; (c) HPS 3. (d) Amount of energy generated and consumed for HPS 1, HPS 2 and HPS 3.

The design of the DTC influences the annual number of production cycles and therefore the amount of electricity generated. The electricity generated is reduced from 226.46 to $203.00 \mathrm{GWh} \mathrm{year}^{-1}$ in HPS 1, from 391.19 to $350.16 \mathrm{GWh}_{\text {year }}{ }^{-1}$ in HPS 2 and from 789.73 to $701.32 \mathrm{GWh}_{\text {year }}{ }^{-1}$ in HPS 3 when the DTC increases from 4 to $10 \mathrm{~h}$. The maximum theoretical income reaches $49.06 \mathrm{M} €$ year ${ }^{-1}$ and is obtained in HPS 3 when the DTC is $4 \mathrm{~h}$. The maximum income is reduced by $16.70 \%$ and the minimum costs are increased by $8.56 \%$ in HPS 3 when the DTC is increased to $10 \mathrm{~h}$. Consequently, the spread between the income from selling electricity and the cost for purchasing electricity is also reduced from 31.59 to $21.91 \mathrm{M}$ year $^{-1}$ in HPS 3 when the DTC increases to $10 \mathrm{~h}$. The maximum incomes reach 13.91 and $24.41 \mathrm{M€}^{-1} \mathrm{ear}^{-1}$ in HPS 1 and HPS 2 when the DTC is $4 \mathrm{~h}$. In addition, 
the spreads between the income and expenses are reduced by $45.86 \%$ and $31.12 \%$ in HPS 1 and HPS 2, respectively, when the DTC increases from 4 to $10 \mathrm{~h} \mathrm{day}^{-1}$.

As a presumable guideline, Table 2 shows the maximum theoretical income and the expenses of the three HPSs when considering a DTC of $8 \mathrm{~h}$. In this scenario, the maximum output powers (turbine mode) for HPS 1, HPS 2 and HPS 3 are 62, 109 and 219 MW, respectively, while the maximum input powers (pumping mode) are 53, 92 and 185 MW for HPS 1, HPS 2 and HPS 3, respectively. The maximum income and the minimum cost for purchasing energy are obtained participating in the day-ahead and the ancillary services markets. The costs for purchasing energy represent $84 \%$, $85 \%$ and $87 \%$ of the total costs in HPS 1, HPS 2 and HPS 3, respectively. In addition, O\&M costs, start-up costs, grid access tariff and hydraulic cannon have been considered. As established in Spanish electrical regulation, a cost of $0.5 € \mathrm{MWh}^{-1}$ has been considered as grid access tariff. O\&M costs include personnel, insurance, spare parts and external service costs. Finally, the operating margins (income from selling electricity minus the cost for purchasing electricity and operation costs) have been estimated, reaching 6.07, 10.99 and $22.71 \mathrm{M}^{-}$year $^{-1}$ in HPS 1, HPS 2 and HPS 3, respectively. Repeating all these considerations when a DTC of $4 \mathrm{~h}$ is designed, the operating margins increase to 7.83, 14.11 and 28.81 M€ year ${ }^{-1}$ in HPS 1, HPS 2 and HPS 3, respectively.

Table 2. Income and operation costs of HPS 1, HPS 2 and HPS 3, considering a DTC of $8 \mathrm{~h}$.

\begin{tabular}{|c|c|c|c|}
\hline UPSH Operation & HPS 1 & HPS 2 & HPS 3 \\
\hline Electricity generation income $\left(\mathrm{k} €\right.$ year $\left.^{-1}\right)$ & $11,602.55$ & $22,222.67$ & $44,655.73$ \\
\hline Electricity consumption costs $\left(\mathrm{k} €\right.$ year $\left.{ }^{-1}\right)$ & 5582.04 & 9642.45 & $19,284.89$ \\
\hline O\&M $\left({\left.\mathrm{k} € ~ \text { year }^{-1}\right)}^{-}\right.$ & 464.10 & 651.75 & 961.79 \\
\hline Start-up costs $\left(k €\right.$ year $\left.^{-1}\right)$ & 202.88 & 296.79 & 417.47 \\
\hline Grid access tariff $\left(\mathrm{k}\right.$ year $\left.^{-1}\right)$ & 84.47 & 148.27 & 297.95 \\
\hline Hydraulic cannon (k€ year $\left.{ }^{-1}\right)$ & 278.51 & 488.90 & 982.43 \\
\hline Operating margin $\left(\mathrm{k} €\right.$ year $\left.^{-1}\right)$ & 6047.60 & $10,994.52$ & $22,711.22$ \\
\hline
\end{tabular}

\subsection{Feasibility Analysis}

The previous section has revealed that the maximum spreads between the income from selling electricity and the cost for purchasing electricity when participating in the ancillary services markets as well as the operating margins of UPSH plants are significantly reduced when the designed DTC increases from 4 to $10 \mathrm{~h}$. However, when the DTC increases, the output power of the FT decreases and the investment costs of UPSH are reduced. This means that the economic feasibility of UPSH plants strongly depends on the investment costs. To introduce this variable in the analysis, the EBIT, PB, NPV and IRR are shown in Figure 6 for HPS 3, considering an investment cost between 1000 and $3000 € \mathrm{~kW}^{-1}$ for DTCs between 4 and $10 \mathrm{~h}$. In this scenario, a UPSH plant with surface upper reservoir is considered (Figure 2a). Although the lifetime of UPSH plants could be between 60 and 100 years, a typical operation time of 35 years has been considered here in order to calculate the amortization costs [32,33]. Due to amortization costs, the EBIT decrease in all DTCs when the investment costs increase from 1000 to $3000 € \mathrm{~kW}^{-1}$ (see Figure 6a). The red line represents the limits where the EBIT turn into negative numbers. Precisely, the minimum EBIT are $-8.32 \mathrm{M}$ year $^{-1}$ when the investment cost is $3000 € \mathrm{~kW}^{-1}$ and the DTC is $4 \mathrm{~h}$.

In Figure $6 \mathrm{~b}$, a minimum PB of 9 years is obtained when the investment cost is $1000 € \mathrm{~kW}^{-1}$ and the DTC is $10 \mathrm{~h}$. The PB increases to 34 years when the investment cost is $3000 € \mathrm{~kW}^{-1}$ and the DTC is $4 \mathrm{~h}$. PBs lower than or equal to 20 years are reached when the investment costs are lower than $2000 € \mathrm{~kW}^{-1}$ and the DTC is greater than $6 \mathrm{~h}$. In Figure $6 \mathrm{~b}$, the NPV decreases sharply when the investment cost increases. Again, a red line represents the border between positive and negative values. An NPV of $-581 \mathrm{M} €$ is reached when the investment cost is $3000 € \mathrm{~kW}^{-1}$. The NPV increases to $294 \mathrm{M} €$ when the investment cost is reduced to $1000 € \mathrm{~kW}^{-1}$ and the designed DTC is $10 \mathrm{~h}$. Finally, a maximum IRR of $12.92 \%$ is obtained when the investment costs are $1000 € \mathrm{~kW}^{-1}$ and the DTC is $10 \mathrm{~h}$. 
IRRs greater than or equal to $6 \%$ are reached when the investment costs are lower than $2000 € \mathrm{~kW}^{-1}$ and the DTC is greater than $5 \mathrm{~h}$.

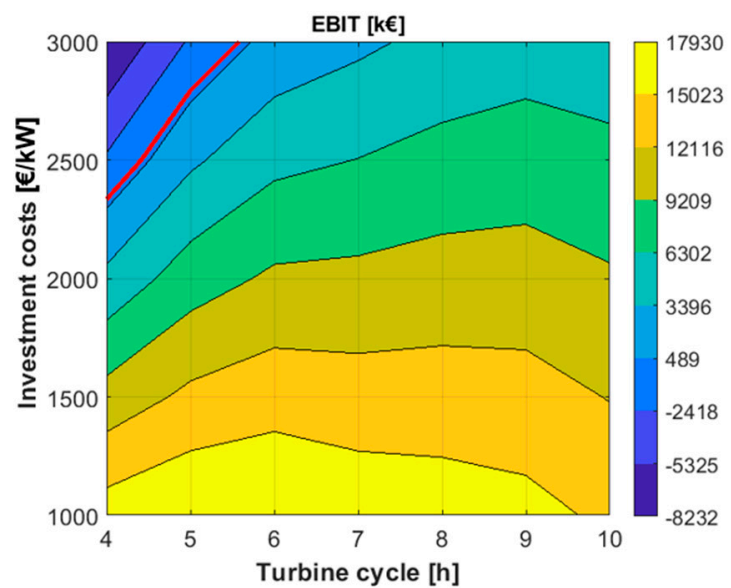

(a)

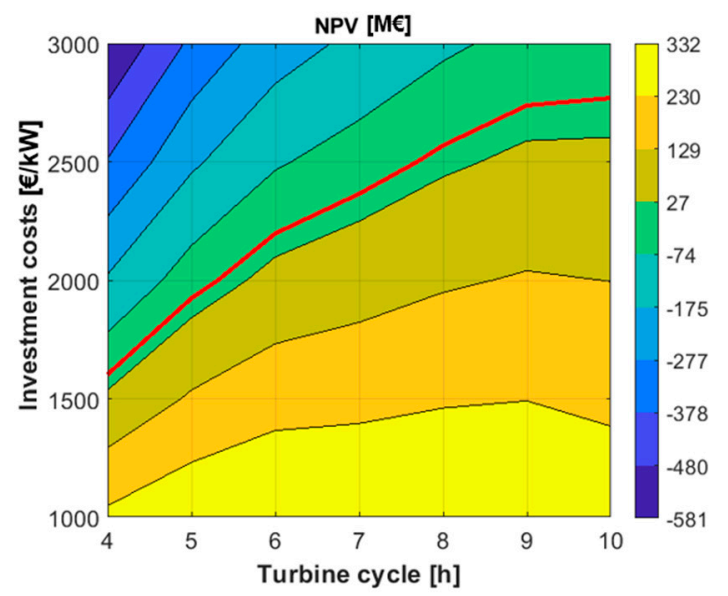

(c)

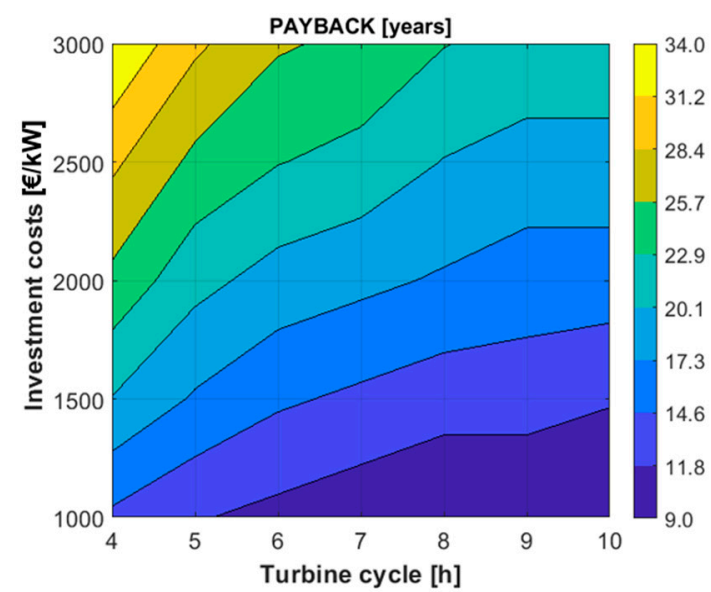

(b)

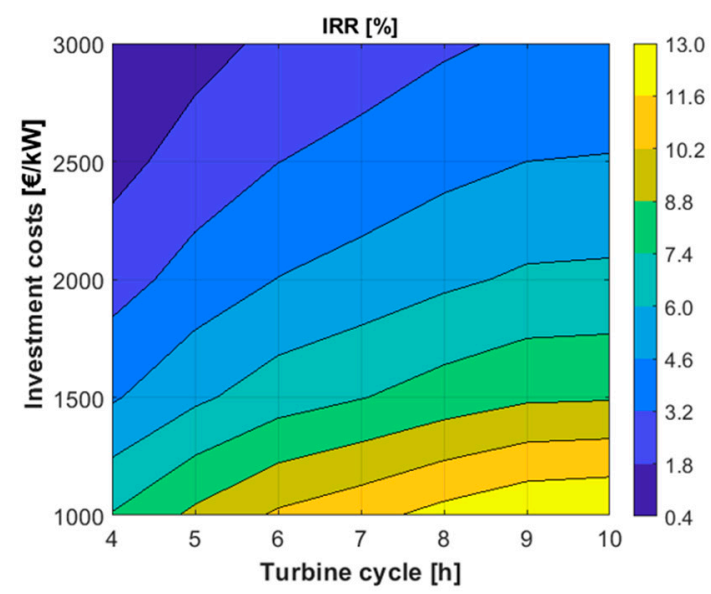

(d)

Figure 6. Feasibility analysis of HPS 3 with surface upper reservoir, considering DTCs between 4 and $10 \mathrm{~h}$ and investment costs between 1000 and $3000 € \mathrm{~kW}^{-1}$. (a) Earnings before interest and taxes (EBIT), where the red line represents zero EBIT; (b) payback period; (c) net present value (NPV), where the red line represents zero NPV; (d) internal rate of return.

According to the calculated investment costs, the profitability of each HPS is finally presented in Table 3, considering a DTC of $8 \mathrm{~h}$ as well as the digging of new caverns or tunnels as a lower reservoir for UPSH plants, where an investment cost of $3138 € \mathrm{~kW}^{-1}$ was estimated in Section 3.1. A pumping cycle time of $10.64 \mathrm{~h}$ has been assumed. As indicated previously, maximum output powers of 62, 109 and 219 MW have been considered for HPS 1, HPS 2 and HPS 3, respectively. The EBIT increase

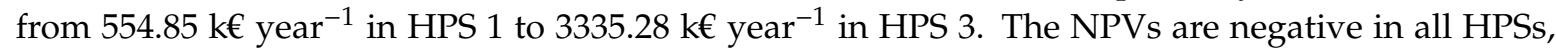
while the IRRs obtained are lower than $2.75 \%$. Finally, high PBs (greater than 24 years) have been reached. Therefore, the construction of new underground infrastructure as the lower reservoir of a UPSH plant is not economically feasible. 
Table 3. Profitability analysis of HPS 1, HPS 2 and HPS 3, considering the construction of new tunnels or caverns, DTCs of $8 \mathrm{~h}$ and a lifetime of 35 years.

\begin{tabular}{cccc}
\hline EBIT and Profitability & HPS 1 & HPS 2 & HPS 3 \\
\hline EBIT (k€ year ${ }^{-1}$ ) & 554.85 & 1352.20 & 3335.28 \\
NPV (k€) & $-41,570.22$ & $-65,194.66$ & $-118,307.90$ \\
IRR (\%) & $2.43 \%$ & $2.61 \%$ & $2.75 \%$ \\
PB (years) & 25 & 25 & 24 \\
\hline
\end{tabular}

The profitability analysis of HPS 1, HPS 2 and HPS 3 is shown in Table 4, considering an investment cost of $1675 € \mathrm{~kW}^{-1}$ (estimated in Section 3.1) and a DTC of $8 \mathrm{~h}$. The results obtained when the existing underground infrastructure is used are much better than those of the previous scenario. The maximum NPV is 185.70 M€ and has been obtained in HPS 3, while the IRR increases to $7.10 \%$. The minimum IRR is reached in HPS 1 (6.6\%). Finally, the minimum PBs decrease to 15 years in all HPSs. This demonstrates that a UPSH plant could become economically feasible using the existing infrastructure and participating in the ancillary services markets.

Table 4. Profitability analysis of HPS 1, HPS 2 and HPS 3, making use of existing infrastructure and considering DTCs of $8 \mathrm{~h}$ and a lifetime of 35 years.

\begin{tabular}{cccc}
\hline EBIT and Profitability & HPS 1 & HPS 2 & HPS 3 \\
\hline EBIT (k€ year $^{-1}$ ) & 3115.57 & 5847.65 & $12,368.74$ \\
NPV (k€) & $44,614.77$ & $86,094.49$ & $185,702.73$ \\
IRR (\%) & $6.66 \%$ & $6.90 \%$ & $7.10 \%$ \\
PB (years) & 15 & 15 & 15 \\
\hline
\end{tabular}

\subsection{Design Considerations of UPSH Plants}

The proper dimensioning of a UPSH plant is highly important for optimizing its economic feasibility. The net head and the amount of water moved must be maximized for increasing the storable amount of energy and the economic feasibility. Although the amount of energy remains constant, different dimensioning of UPSH could be carried out depending on the DTC. When the DTC increases, the output power of the FT decreases, consequently reducing the investment costs. DTCs greater than $7 \mathrm{~h}$ would be suitable for UPSH plants. The profitability also depends on the lifetime considered. Therefore, the profitability analysis was carried out considering lifetimes of 50 and 75 years. In addition, when the lifetime is increased, the amortization costs decrease and the EBIT increase.

Table 5 shows the NPVs, IRRs and PBs for HPS 1, HPS 2 and HPS 3 when considering the construction of new tunnels or caverns as a lower reservoir. The NPVs and IRRs of HPS 1, HPS 2 and HPS 3 increase with respect to the scenario that considers a lifetime of 35 years. However, IRRs lower than $5 \%$ and NPVs lower than $167.88 \mathrm{M} €$ are reached for 75 years, and therefore the projects are not economically feasible.

Table 5. Profitability analysis of HPS 1, HPS 2 and HPS 3, considering the construction of new tunnels, DTCs of $8 \mathrm{~h}$ and lifetimes of 50 and 75 years.

\begin{tabular}{ccccccc}
\hline Lifetime & \multicolumn{3}{c}{ 50 Years } & \multicolumn{3}{c}{ 75 Years } \\
\hline HPS & HPS 1 & HPS 2 & HPS 3 & HPS 1 & HPS 2 & HPS 3 \\
\hline NPV (k€) & -3017.07 & 4110.40 & $23,617.80$ & $36,419.81$ & $74,753.03$ & $167,882.32$ \\
IRR (\%) & $3.92 \%$ & $4.06 \%$ & $4.17 \%$ & $4.68 \%$ & $4.79 \%$ & $4.88 \%$ \\
PB (years) & 25 & 25 & 25 & 25 & 25 & 25 \\
\hline
\end{tabular}


Table 6 shows the profitability analysis for lifetimes of 50 and 75 years in UPSH plants where the existing infrastructure is used as a lower reservoir. The NPV and the IRR reach $471.89 \mathrm{M} €$ and $8.13 \%$ when the lifetime of the UPSH increases to 75 years. The NPVs of HPS 3 for a lifetime of 75 years are increased by $284 \%$ and $108 \%$ in comparison with the values obtained for HPS 1 and HPS 2, respectively. Finally, the PB remains constant in each HPS.

Table 6. Profitability analysis of HPS 1, HPS 2 and HPS 3, making use of existing infrastructure and considering DTCs of $8 \mathrm{~h}$ and lifetimes of 50 and 75 years.

\begin{tabular}{ccccccc}
\hline Lifetime & \multicolumn{3}{c}{ 50 Years } & \multicolumn{3}{c}{ 75 Years } \\
\hline HPS & HPS 1 & HPS 2 & HPS 3 & HPS 1 & HPS 2 & HPS 3 \\
\hline NPV (k€) & $83,167.91$ & $155,399.55$ & $327,628.43$ & $122,604.79$ & $226,042.18$ & $471,892.95$ \\
IRR (\%) & $7.47 \%$ & $7.68 \%$ & $7.86 \%$ & $7.78 \%$ & $7.97 \%$ & $8.13 \%$ \\
PB (years) & 15 & 15 & 15 & 15 & 15 & 15 \\
\hline
\end{tabular}

\subsection{Comparison with Other Storage Technologies}

The installation cost of energy storage technologies $\left(€ \mathrm{kWh}^{-1}\right)$ has been compared with UPSH plants. Figure 7 shows the planned installation cost of a number of energy storage types for 2030 and highlights the low cost of conventional PSH $\left(19 € \mathrm{kWh}^{-1}\right)$, followed by CAES systems $\left(38.26 € \mathrm{kWh}^{-1}\right)$ [2,34]. Electrochemical storage like lithium-ion is still more expensive to install, but it is more efficient at storing and releasing energy, opening it up to a wider range of potential applications [34]. The installation cost of UPSH plants using the existing infrastructure reaches $20.90 € \mathrm{kWh}^{-1}$, while the cost of UPSH considering the excavation of new tunnels increases to $38 € \mathrm{kWh}^{-1}$.

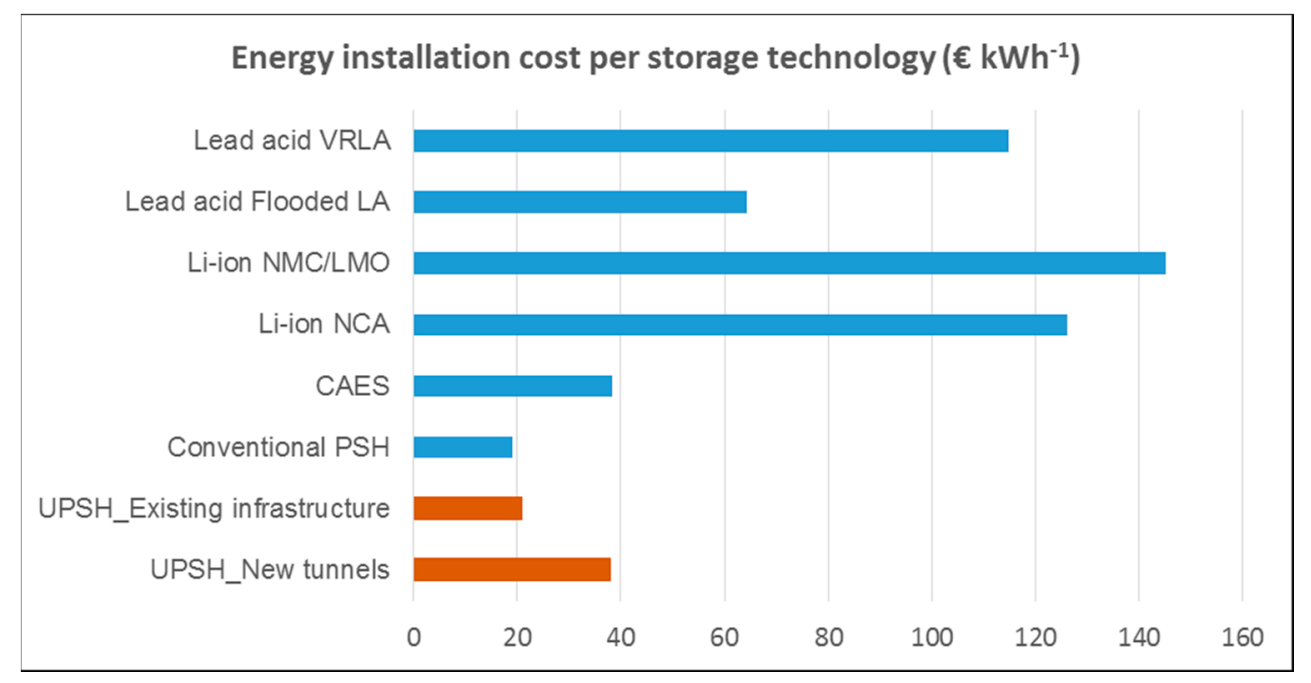

Figure 7. Energy installation cost of battery storage technologies vs. UPSH plants.

\section{Conclusions}

The economic feasibility of UPSH plants participating in the day-ahead and ancillary services markets in the Iberian electricity system is presented for three HPSs. A deterministic model has been applied in order to maximize the income and minimize the costs for purchasing electricity. Different DTCs between 4 and $10 \mathrm{~h}$ have been considered in order to evaluate the economic feasibility of UPSH plants. In addition, the investment costs when making use of existing underground infrastructure and when excavating new tunnels or caverns as a lower reservoir have been estimated in order to evaluate the profitability of the investment. 
The results obtained show that the number of annual production cycles and the amount of electricity generated decrease when the DTC increases. The maximum number of annual production cycles is 360 when the DTC is $4 \mathrm{~h}$ and decreases to 323 when the DTC increases to $10 \mathrm{~h}$. Although the spread between the income from selling electricity and the costs for purchasing energy decreases when the DTC increases, the operating margin increases due to investment costs. In the profitability model, IRRs greater than or equal to $6 \%$ are reached when the investment costs are lower than $2000 € \mathrm{~kW}^{-1}$ and the DTC is greater than $5 \mathrm{~h}$. In general, it can be concluded that the IRR increases when the investment costs decrease and the DTC increases.

A UPSH plant is not economically feasible when new infrastructure has to be built. Maximum IRRs of $2.43 \%, 2.61 \%$ and $2.75 \%$ have been obtained for HPS 1, HPS 2 and HPS 3, respectively, with a minimum PB of around 24 years. On the contrary, the investment cost of a UPSH plant is reduced by $46.6 \%\left(1675 € \mathrm{~kW}^{-1}\right)$ when the existing underground infrastructure is used as a lower reservoir. Under these conditions, a UPSH plant could be economically feasible (IRRs greater than $6 \%$ and PBs lower than 15 years) when participating in the ancillary services markets, dimensioning DTCs greater than $6 \mathrm{~h}$ and using the existing underground infrastructure as a lower reservoir.

Author Contributions: Conceptualization, J.M.; investigation, J.M., J.M.F.-O. and J.L.; methodology, J.M.; software, J.M. and J.M.F.-O.; validation, J.M. and J.M.F.-O.; writing—original draft, J.M.; writing—review and editing, J.M. and J.M.F.-O.; supervision, J.L. All authors have read and agreed to the published version of the manuscript.

Funding: This research received no external funding.

Conflicts of Interest: The authors declare no conflict of interest.

\section{Nomenclature}

A-CAES Adiabatic compressed air energy storage

CAES Compressed air energy storage

DTC Daily turbine cycle time at full load

EBIT Earnings before interest and taxes

ESS Energy storage system

FT Francis pump-turbine

HPS Hydropower station

IRR Internal rate of return

LA Lead-acid

Li-ion Lithium ion

LMO Lithium manganese oxide

MISO Mid-continent Independent System Operator

NPV Net present value

NCA Nickel cobalt aluminum

NMC Nickel manganese cobalt

NYISO New York Independent System Operator

O\&M Operation and maintenance

PB Payback period

PSH Pumped storage hydropower

PV Photovoltaic

RES Renewable energy sources

UPSH Underground pumped storage hydropower

VRLA Valve-regulated lead-acid 


\section{Appendix A}

Table A1. Assessment of the investment costs of a UPSH plant, considering an FT with 219 MW of output power and a DTC of $8 \mathrm{~h}$. Civil works, hydromechanical equipment and penstock, hydropower equipment, electric substation and grid connection.

\begin{tabular}{|c|c|}
\hline \multicolumn{2}{|l|}{ UPSH-Investment Cost (k€) } \\
\hline Civil works & $525,692.80$ \\
\hline Surface works & $31,110.40$ \\
\hline Upper reservoir & $30,730.00$ \\
\hline Excavation and support & $23,680.00$ \\
\hline Waterproofing & 7050.00 \\
\hline Electric substation & 380.40 \\
\hline Underground works & $494,582.40$ \\
\hline Tunnel of access & $24,923.30$ \\
\hline Excavation and support system & $24,800.00$ \\
\hline Lighting system & 48.50 \\
\hline Ventilation system & 74.80 \\
\hline Powerhouse cavern & $12,555.63$ \\
\hline Excavation and support system & 8950.00 \\
\hline Cavern equipment & 2485.00 \\
\hline Vent shaft and electric cables & 975.30 \\
\hline Drainage drift & 145.33 \\
\hline Lower reservoir & $453,333.33$ \\
\hline Submergence tunnel & 2550.00 \\
\hline Vent shaft & 652.40 \\
\hline Surge tank & 567.74 \\
\hline Hydromechanical equipment and penstock & $16,986.52$ \\
\hline Intake & 3280.00 \\
\hline Penstock & 4056.00 \\
\hline Auxiliary systems & 9650.52 \\
\hline Hydropower equipment & $99,709.12$ \\
\hline Francis pump-turbine & $37,640,85$ \\
\hline Motor-generator & $35,321.85$ \\
\hline Electrical and control systems & $25,895.53$ \\
\hline Fire protection system & 850.90 \\
\hline Electrical grid connection & 4510.50 \\
\hline Electric substation & 3250.30 \\
\hline Powerline & 1260.20 \\
\hline Total Cost (k€) & $639,209.18$ \\
\hline
\end{tabular}


Table A2. Assessment of the investment costs of a UPSH plant, considering an FT with 219 MW of output power and a DTC of $8 \mathrm{~h}$. Commissioning and project management.

\begin{tabular}{lc}
\hline \multicolumn{2}{c}{ UPSH-Investment Cost (k€) } \\
\hline Commissioning & $\mathbf{4 1 4 0 . 8 5}$ \\
\hline Spare parts and staff training & 895.30 \\
Civil and structure works and penstock & 450.20 \\
Mechanical review & 790.25 \\
Electrical review & 675.80 \\
Control system review & 560.40 \\
Commissioning testing & 768.90 \\
\hline Project management & $\mathbf{3 6 , 3 0 1 . 3 0}$ \\
\hline Building permits and others & $16,950.00$ \\
Engineering & 3250.00 \\
Construction management & 4230.90 \\
Security and health & 2420.40 \\
Waste management & 9450.00 \\
\hline Total Cost (k€) & $\mathbf{4 0 , 4 4 2 . 1 5}$ \\
\hline
\end{tabular}

\section{UPSH PLANT - INVESTMENT COST ANALYSIS - TURBINE 2 (219 MW) SURFACE UPPER RESERVOIR}

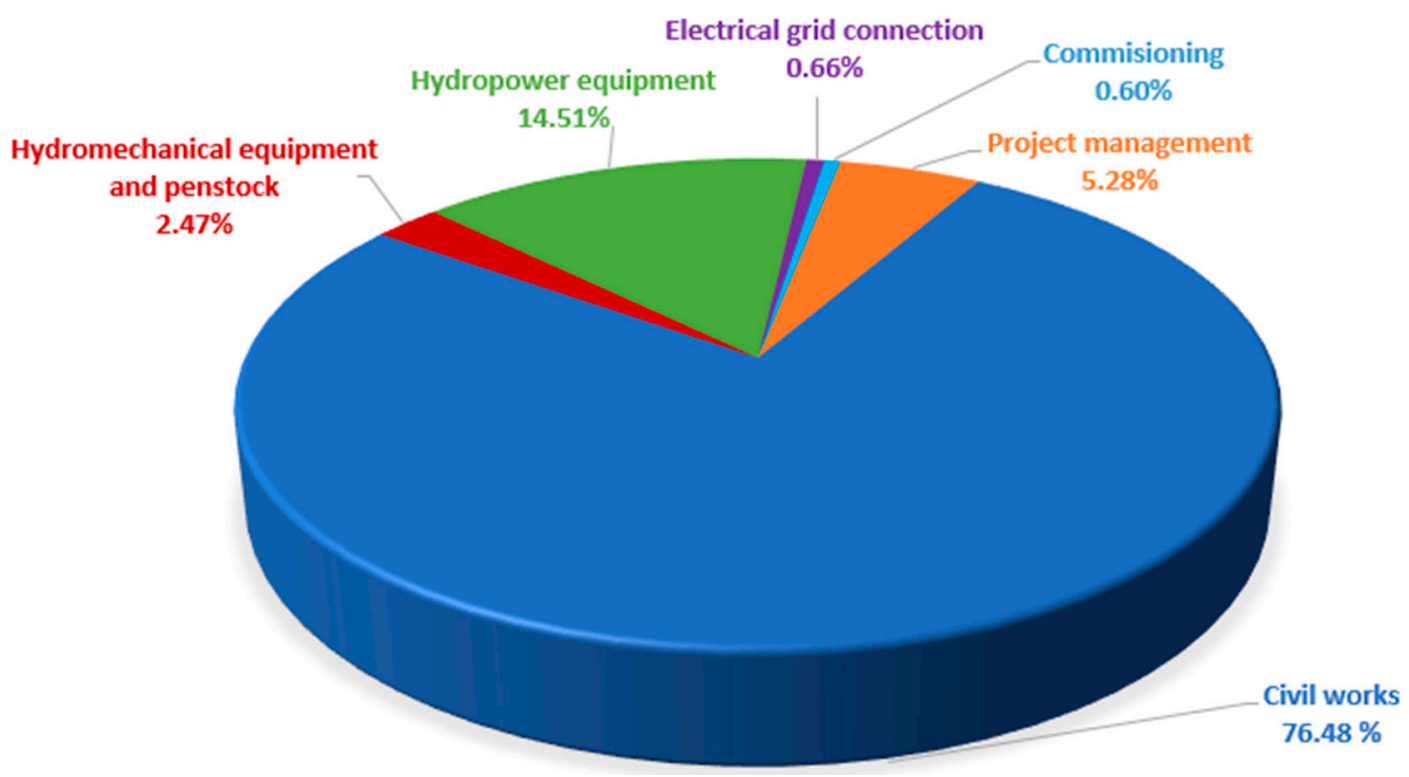

Figure A1. Capital cost breakdown for a UPSH plant with surface upper reservoir and underground lower reservoir.

\section{References}

1. Weron, R. Electricity price forecasting: A review of the state-of-the-art with a look into the future. Int. J. Forecast 2014, 30, 1030-1081. [CrossRef]

2. Mongird, K.; Fotedar, V.; Viswanathan, V.; Koritarov, V.; Balducci, P.; Hadjerioua, B.; Alam, J. Energy Storage Technology and Cost Characterization Report; U.S. Department of Energy's Water Power Technologies Office by Pacific Northwest National Laboratory: Washington, DC, USA, 2019.

3. Matos, C.R.; Carneiro, J.F.; Silva, P.P. Overview of large-scale underground energy storage technologies for integration of renewable energies and criteria for reservoir identification. J. Energy Storage 2019, 21, 241-258. [CrossRef] 
4. Pummer, E.; Schüttrumpf, H. Reflection phenomena in underground pumped storage reservoirs. Water 2018, 10, 504. [CrossRef]

5. Tola, V.; Meloni, V.; Spadaccini, F.; Cau, G. Performance assessment of Adiabatic Compressed Air Energy Storage (A-CAES) power plants integrated with packed-bed thermocline storage systems. Energy Convers. Manag. 2017, 151, 343-356. [CrossRef]

6. Menendez, J.; Fernández-Oro, J.M.; Galdo, M.; Loredo, J. Efficiency analysis of underground pumped storage hydropower plants. J. Energy Storage 2020, 28, 101234. [CrossRef]

7. Winde, F.; Kaiser, F.; Erasmus, E. Exploring the use of deep level gold mines in South Africa for underground pumped hydroelectric energy storage schemes. Renew. Sustain. Energy Rev. 2016, 78, 668-682. [CrossRef]

8. Winde, F.; Stoch, E.J. Threats and opportunities for post-closure development in dolomitic gold mining areas of the West Rand and Far West Rand (South Africa)—A hydraulic view part 1: Mining legacy and future threats. Water $S A$ 2010, 36, 69-74. [CrossRef]

9. Pujades, E.; Orban, P.; Archambeau, P.; Erpicum, S.; Dassargues, A. Numerical study of the Martelange mine to be used as underground reservoir for constructing an Underground Pumped Storage Hydropower plant. Adv. Geosci. 2018, 45, 51-56. [CrossRef]

10. Pujades, E.; Orban, P.; Archambeau, P.; Kitsikoudis, V.; Erpicum, S.; Dassargues, A. Underground Pumped-Storage Hydropower (UPSH) at the Martelange Mine (Belgium): Interactions with Groundwater Flow. Energies 2020, 13, 2353. [CrossRef]

11. Bodeux, S.; Pujades, E.; Orban, P.; Brouyère, S.; Dassargues, A. Interactions between groundwater and the cavity of an old slate mine used as lower reservoir of an UPSH (Underground Pumped Storage Hydroelectricity): A modelling approach. Eng. Geol. 2016, 217, 71-80. [CrossRef]

12. Menendez, J.; Loredo, J.; Galdo, M.; Fernandez-Oro, J.M. Energy storage in underground coal mines in NW Spain: Assessment of an underground lower water reservoir and preliminary energy balance. Renew. Energy. 2019, 134, 1381-1391. [CrossRef]

13. Menéndez, J.; Ordóñez, A.; Álvarez, R.; Loredo, J. Energy from closed mines: Underground energy storage and geothermal applications. Renew. Sustain. Energy Rev. 2019, 108, 498-512. [CrossRef]

14. Madlener, R.; Specht, J.M. An Exploratory Economic Analysis of Underground Pumped-Storage Hydro Power Plants in Abandoned Coal Mines; FCN Working Paper No. 2/2013; FCN: Aachen, Germany, 2013.

15. Menéndez, J.; Fernández-Oro, J.M.; Galdo, M.; Loredo, J. Transient Simulation of Underground Pumped Storage Hydropower Plants Operating in Pumping Mode. Energies 2020, 13, 1781. [CrossRef]

16. Wong, I.H. An underground pumped storage scheme in the Bukit Timah granite of Singapore. Tunn. Undergr. Space Technol. 1996, 11, 485-489. [CrossRef]

17. Graves, F.; Jenkin, T.; Murphy, D. Opportunities for electricity storage in deregulating markets. Electr. J. 1999, 12, 46-56. [CrossRef]

18. Connolly, D.; Lund, H.; Finn, P.; Mathiesen, B.V.; Leahy, M. Practical operation strategies for pumped hydroelectric energy storage (PHES) utilising electricity price arbitrage. Energy Policy 2011, 39, 4189-4196. [CrossRef]

19. Lobato, E.; Egido, I.; Rouco, L.; López, G. An overview of ancillary services in Spain. Electr. Power Syst. Res. 2008, 78, 515-523. [CrossRef]

20. Pérez-Díaz, J.I.; Chazarra, M.; García-González, J.; Cavazzini, G.; Stoppato, A. Trends and challenges in the operation of pumped-storage hydropower plants. Renew. Sustain. Energy Rev. 2015, 44, 767-784. [CrossRef]

21. Krishnan, V.; Das, T. Optimal allocation of energy storage in a co-optimized electricity market: Benefits assessment and deriving indicators for economic storage ventures. Energy 2015, 81, 175-188. [CrossRef]

22. Berrada, A.; Loudiyi, K.; Zorkani, I. Valuation of energy storage in energy and regulation markets. Energy 2016, 115, 1109-1118. [CrossRef]

23. Chazarra, M.; Pérez-Díaz, J.I.; García-González, J.; Praus, R. Economic viability of pumped-storage power plants participating in the secondary regulation service. Appl. Energy 2018, 216, 224-233. [CrossRef]

24. Maciejowska, K.; Nitka, W.; Weron, T. Day-Ahead vs. Intraday-Forecasting the Price Spread to Maximize Economic Benefits. Energies 2019, 12, 631. [CrossRef]

25. Ekman, C.K.; Jensen, S.H. Prospects for large scale electricity storage in Denmark. Energy Convers. Manag. 2010, 51, 1140-1147. [CrossRef] 
26. Chazarra, M.; Pérez-Díaz, J.; García-González, J. Optimal Operation of Variable Speed Pumped Storage Hydropower Plants Participating in Secondary Regulation Reserve Markets. In Proceedings of the 2014 11th International Conference on the European Energy Market (EEM), Krakow, Poland, 28-30 May 2014.

27. Chazarra, M.; García-González, J.; Pérez-Díaz, J.I.; Arteseros, M. Stochastic optimization model for the weekly scheduling of a hydropower system in day-ahead and secondary regulation reserve markets. Electr. Power Syst. Res. 2016, 130, 67-77. [CrossRef]

28. Min, C.-G.; Kim, M.-K. Impact of the Complementarity between Variable Generation Resources and Load on the Flexibility of the Korean Power System. Energies 2017, 10, 1719. [CrossRef]

29. Lago, J.; Ridder, F.D.; Vrancx, P.; Schutter, B.D. Forecasting day-ahead electricity prices in Europe: The importance of considering market integration. Appl. Energy 2018, 211, 890-903. [CrossRef]

30. Chazarra, M.; Pérez-Díaz, J.; García-González, J. Optimal Joint Energy and Secondary Regulation Reserve Hourly Scheduling of Variable Speed Pumped Storage Hydropower Plants. IEEE Trans. Power Syst. 2018, 33, 103-115. [CrossRef]

31. Steffen, B. Prospects for pumped-hydro storage in Germany. Energy Policy 2012, 45, 420-429. [CrossRef]

32. Pearre Nathaniel, S.; Swan Lukas, G. Technoeconomic feasibility of grid storage: Mapping electrical services and energy storage technologies. Appl. Energy 2015, 137, 501-510. [CrossRef]

33. Ardizzon, G.; Cavazzini, G.; Pavesi, G. A new generation of small hydro and pumped hydro power plants: Advances and future challenges. Renew. Sustain. Energy Rev. 2014, 31, 746-761. [CrossRef]

34. IRENA. Electricity Storage and Renewables: Costs and Markets to 2030; International Renewable Energy Agency: Abu Dhabi, UAE, 2017.

(C) 2020 by the authors. Licensee MDPI, Basel, Switzerland. This article is an open access article distributed under the terms and conditions of the Creative Commons Attribution (CC BY) license (http://creativecommons.org/licenses/by/4.0/). 